\title{
Obstrucción de intestino delgado secundaria a hernia paraduodenal izquierda
}

\author{
Small bowel obstruction secondary to left paraduodenal hernia
}

\author{
Fernando Karel Fonseca-Sosa $\mathbb{D}$, Iván Ramón Cutiño-Ocaña² $\mathbb{D}$, Pedro Rafael Casado-Méndez $\mathbb{D}^{\mathbb{D}}$, \\ Alaín Viltres Rodríguez ${ }^{2} \mathbb{D}$ \\ 1. Médico, especialista de primer grado en Cirugía general. Profesor asistente, Hospital Provincial Clínico-Quirúrgico Docente "Celia \\ Sánchez Manduley, Manzanillo, Cuba. \\ 2. Médico, especialista de primer grado en Cirugía general. Profesor instructor, Hospital Provincial Clínico-Quirúrgico Docente "Celia \\ Sánchez Manduley", Manzanillo, Cuba.
}

\section{Presentación del caso}

Se trata de un hombre de 46 años de edad, sin antecedentes de intervención quirúrgica, quién acudió al servicio de urgencias por presentar dolor abdominal tipo cólico, náuseas, vómito bilioso frecuente y ausencia de flatos y deposición. A la exploración física se encontró mucosas secas, abdomen distendido, ruidos hidroaéreos aumentados, hipersonoridad difusa a la percusión y ampolla rectal vacía al tacto rectal. La radiografía simple de abdomen en bipedestación, mostró la presencia de niveles hidroaéreos centrales en escalera y distensión de asas yeyunales e ileales (Figura 1).

Se intervino quirúrgicamente de urgencia, identificándose gran distensión del intestino delgado desde el ligamento de Treitz hasta el íleon terminal, con una hernia paraduodenal izquierda como etiología de la obstrucción intestinal (Figura 2). Se hizo reducción del intestino delgado herniado y cierre del orificio herniario con sutura continua no absorbible (Figura 3). La evolución del paciente fue favorable

\section{Discusión}

Las hernias paraduodenales constituyen el $50 \%$ de todas las hernias abdominales internas, con una incidencia de $0,2 \%$ al $0,9 \%$, y son una causa muy infrecuente de obstrucción del intestino delgado ${ }^{1}$. Las hernias paraduodenales izquierdas son anomalías congénitas que surgen durante la rotación del tracto digestivo, cuando el intestino delgado se invagina en un segmento avascular de mesocolon transverso en la fosa de Landzert ${ }^{2}$. Los métodos imagenológicos son necesarios para el diagnóstico temprano y para planear la cirugía ${ }^{3}$. Los principios del tratamiento quirúrgico incluyen la reducción de la hernia intestinal, la resección del segmento intestinal isquémico, si existe, y el cierre del orificio de la hernia ${ }^{4}$.

Palabras clave: hernia; interna; congénita; paraduodenal; obstrucción intestinal.

Keywords: hernia; internal; congenital; paraduodenal; intestinal obstruction.

Fecha de recibido: 26/06/2020 - Fecha de aceptación: 10/01/2021 - Fecha de publicación en línea: 05/03/2021

Correspondencia: Fernando Karel Fonseca-Sosa, Calle Esperanza No 73 entre Guadalupe y San Javier, Manzanillo, Granma, Cuba. Código Postal 87510. Teléfono: 005323570661. Correo electrónico: ffonsecasosa@gmail.com

Citar como: Fonseca-Sosa FK, Cutiño-Ocaña IR, Casado-Méndez PR, Viltres Rodríguez A. Obstrucción de intestino delgado secundaria a hernia paraduodenal izquierda. Rev Colomb Cir. 2021;36:344-5. https://doi.org/10.30944/20117582.838

Este es un artículo de acceso abierto bajo una Licencia Creative Commons - BY-NC-ND https://creativecommons.org/licenses/by-nc$\mathrm{nd} / 4.0 /$ deed.es 


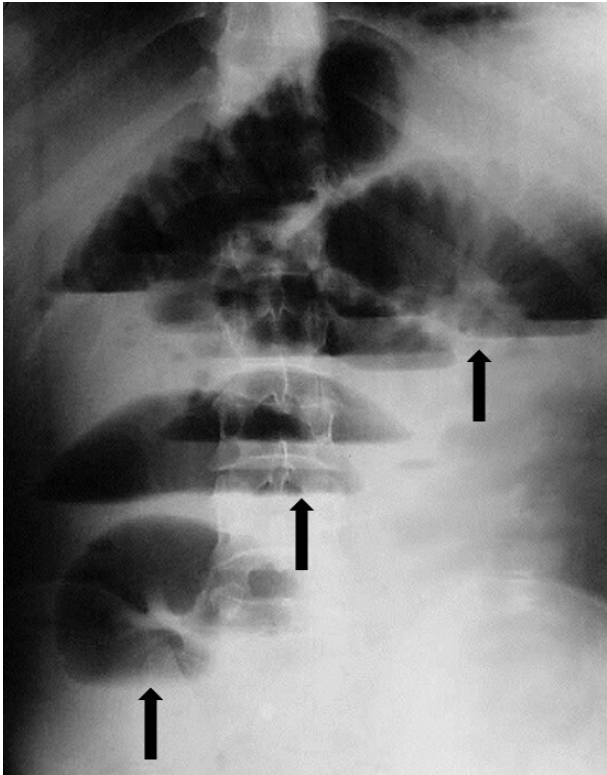

Figura 1. Radiografía simple de abdomen en bipedestación. Las flechas muestran los niveles hidroaéreos centrales en escalera y la distensión de asas yeyunales e ileales.

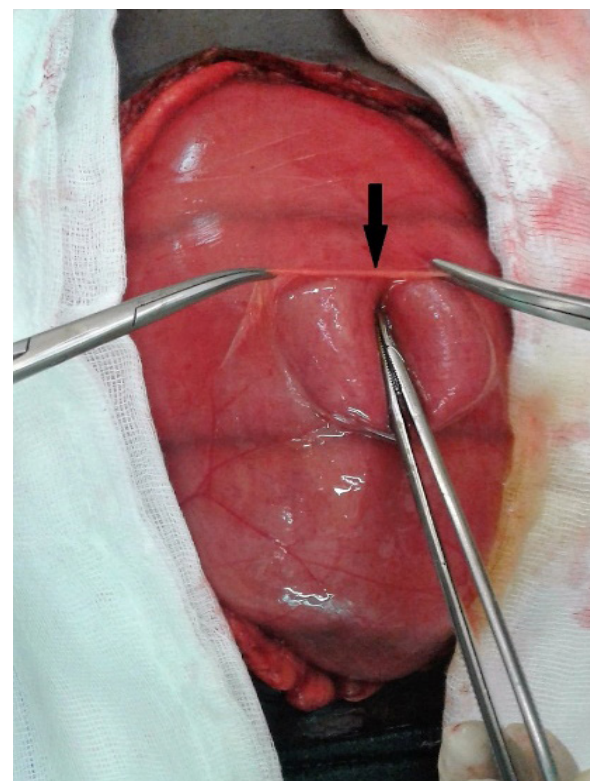

Figura 2. Transoperatorio. La flecha muestra el saco herniario abierto con distensión de asas intestinales delgadas.

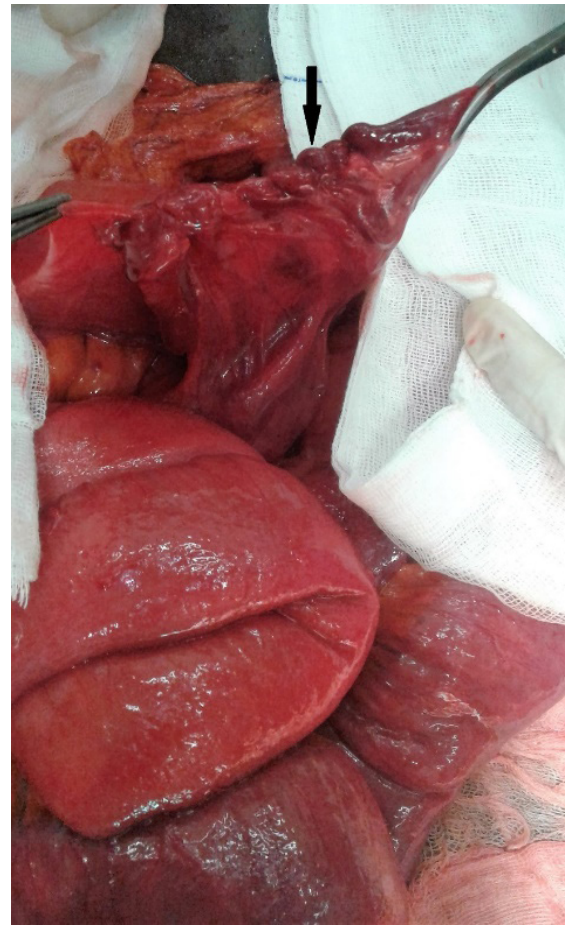

Figura 3. Transoperatorio. Cierre del orificio herniario con sutura continua no absorbible (flecha negra).

\section{Referencias}

1. Muñoz A, Flórez D, Lubinus F, Arias C. Hernias internas: presentación de casos clínicos. Rev Colomb Radiol. 2017;2:4797-4804.

2. Zizzo M, Smerieri N, Barbieri I, Lanaia A, Bonilauri S. Laparoscopic treatment of acute small bowel obstruction due to left paraduodenal hernia: a case report and literature review. Int J Surg Case Reports. 2016;20:87-91. https://doi.org/10.1016/j.ijscr.2016.01.012

3. Atasoy G, Temiz A, Albayrak Y, Yalcin A. A rare case of left paraduodenal hernia: a case report. Arch Clin Exp Med. 2017;2:55-7.

https://doi.org/10.25000/acem.303547

4. Kulkarni GV, Salgaonkar HP, Sharma PC, Chakkarvarty NR, Katara AN, Bhandarkar DS. Laparoscopic repair of left paraduodenal hernia: report of two cases and review of the literature. Asian J Endosc Surg. 2016;9:157-60. https://doi.org/10.1111/ases.12270 